\title{
Comparison of the renal effects of angiotensin converting enzyme inhibitor and calcium antagonist in hypertensive Type 2 (non-insulin-dependent) diabetic patients with microalbuminuria: a randomised controlled trial
}

\author{
T. Baba ${ }^{1}$, S. Murabayashi ${ }^{2}$ and K. Takebe ${ }^{2}$ \\ ${ }^{1}$ Department of Metabolic Diseases and Nutrition, University of Düsseldorf, FRG, and ${ }^{2}$ Third Department of Internal Medicine, Hirosaki \\ University School of Medicine, Hirosaki, Japan
}

\begin{abstract}
Summary. Seven of eight hypertensive Type 2 (non-insulindependent) diabetic patients with microalbuminuria completed a randomised crossover trial to compare the renal effects of angiotensin converting enzyme inhibitor (enalapril) and calcium antagonist (nicardipine). Four-week fixed oral maintenance dosages of enalapril (10-20 mg/day) and nicardipine $(60-120 \mathrm{mg} /$ day) significantly $(p<0.05)$ lowered the systolic and diastolic blood pressures without altering renal blood flow, glomerular filtration rate and filtration fraction. Both drugs significantly reduced $(p<0.05)$ urinary albumin excretion rate and fractional clearance of albumin to similar extents. Total renal vascular resistance decreased significantly by nicardipine $(p<0.05)$ and non-significantly by enalapril. Plasma osmotic pressure, plasma aldosterone concentration, total serum protein concentration, serum electrolytes and $\mathrm{HbA}_{1 \mathrm{c}}$ remained unchanged by these drugs, whereas plasma
\end{abstract}

renin activity was significantly higher $(p<0.05)$ in the enalapril than in the control and nicardipine phases. These results suggest that both drugs have similar renal function preserving effects with a concomitant hypotensive action in hypertensive Type 2 diabetic patients with microalbuminuria, and that the angiotensin converting enzyme inhibitor may not have advantageous renal effects when compared to the calcium antagonist and vice versa. Both drugs might be useful for treatment of high blood pressure in hypertensive diabetic patients, if long-term studies of these drugs can be shown to benefit the patients over other conventional antihypertensive therapies.

Key words: Hypertension, Type 2 (non-insulin-dependent) diabetic patients, microalbuminuria, kidney function, angiotensin converting enzyme inhibitor, calcium antagonist, diabetic nephropathy, antihypertensive therapy.
Hypertension contributes to the leading causes of morbidity and mortality in diabetic patients, such as coronary heart disease and endstage renal disease [1]. Hypertension is often associated with diabetic nephropathy [2], and effective antihypertensive treatment has proven to be effective in slowing the progression rate of nephropathy [3-5]. Recent studies in patients with diabetic nephropathy suggest that the use of angiotensin converting enzyme (ACE) inhibitors may possess specific advantages in decreasing proteinuria and slowing progression of nephropathy [6-9]. Nevertheless, whether such renal effects can be seen only with ACE inhibitors or whether ACE inhibitors have more beneficial renal effects as compared to other conventional antihypertensive drugs is uncertain. Most of the clinical trials on ACE inhibitors in these patients lack a controlled comparison with other active antihypertensive drug(s).

In Type 2 (non-insulin-dependent) diabetic patients, the major cause of the increased morbidity and mor- tality is cardiovascular diseases [10]. Beta-blockers and calcium antagonists are widely used groups of medication for treatment of hypertension and/or ischaemic heart disease(s) in these patients. The use of such drugs appears to be a rational choice since these drugs possess both hypotensive and cardioprotective properties [11]. A few clinical studies have suggested that calcium antagonists lower blood pressure without deterioration of renal function in hypertensive patients [12-15] or even improve the renal function in hypertensive patients with kidney impairment [13]. These observations may suggest that calcium antagonists might also have a promising potential for the treatment of hypertension in diabetic patients with nephropathy.

The present study was designed to investigate and compare the renal effects of oral maintenance doses of ACE inhibitor, enalapril, and calcium antagonist, nicardipine, in hypertensive Type 2 diabetic patients with microalbuminuria. 
Table 1. Clinical characteristics of patients in pretrial period

\begin{tabular}{|c|c|c|c|c|c|c|c|c|c|c|}
\hline Patient & $\begin{array}{l}\text { Age } \\
\text { (years) }\end{array}$ & Sex & $\begin{array}{l}\text { BMI } \\
\left(\mathrm{kg} / \mathrm{m}^{2}\right)\end{array}$ & $\begin{array}{l}\text { SBP } \\
(\mathrm{mm} \mathrm{Hg})\end{array}$ & $\begin{array}{l}\text { DBP } \\
(\mathrm{mm} \mathrm{Hg})\end{array}$ & $\begin{array}{l}\text { Serum } \\
\text { creatinine } \\
(\mu \mathrm{mol} / 1)\end{array}$ & $\begin{array}{l}\text { AER } \\
(\mu \mathrm{g} / \mathrm{min})\end{array}$ & $\begin{array}{l}\text { Duration } \\
\text { of diabetes } \\
\text { (years) }\end{array}$ & Retinopathy & Treatment \\
\hline 1 & 46 & M & 25.8 & 152 & 106 & 80 & 72.0 & 5 & Normal & Diet \\
\hline 2 & 65 & $\mathrm{~F}$ & 21.8 & 172 & 98 & 71 & 40.8 & 8 & Background & Diet \\
\hline 3 & 45 & M & 25.6 & 162 & 102 & 88 & 85.8 & 10 & Background & $\mathrm{OHA}$ \\
\hline 4 & 54 & M & 21.9 & 160 & 100 & 80 & 37.5 & 16 & Background & Insulin \\
\hline 5 & 58 & $\mathrm{M}$ & 20.8 & 162 & 100 & 124 & 44.0 & 15 & Background & Diet \\
\hline 6 & 57 & $\mathrm{M}$ & 25.1 & 178 & 104 & 106 & 66.6 & 6 & Normal & Diet \\
\hline 7 & 56 & $\mathrm{~F}$ & 25.8 & 180 & 104 & 45 & 105.0 & 7 & Background & Diet \\
\hline
\end{tabular}

$\mathrm{BMI}=$ body mass index; $\mathrm{SBP}=$ systolic blood pressure; $\mathrm{DBP}=$ diastolic blood pressure; $\mathrm{AER}=$ urinary albumin excretion rate; $\mathrm{OHA}=$ oral hypoglycaemic agent. The AER is the mean of three measurements using $24 \mathrm{~h}$ samples

\section{Subjects and methods}

\section{Patients}

Eight hypertensive Japanese patients with Type 2 diabetes mellitus were studied. The patients were selected on the bases of age (45-65 years), normal serum creatinine level $(45-130 \mu \mathrm{mol} / \mathrm{l})$, increased urinary albumin excretion $(41-105 \mathrm{mg} /$ day) and negative urine culture. The study was performed after an informed consent had been obtained from each patient. Secondary hypertension was excluded by routine screening test, as previously described [16]. Patients with heart failure, symptomatic coronary heart disease, respiratory disease, tachyarrythmia, liver dysfunction, or clinical or laboratory evidence of other renal disease were also excluded from the study. No drugs (except oral hypoglycaemic agent and insulin) were given for at least 2 weeks before the study.

The diagnosis of hypertension was confirmed when the mean of two or more diastolic and systolic blood pressures on at least two separate occasions within 1 month were $>95 \mathrm{~mm} \mathrm{Hg}$ or $>160 \mathrm{~mm} \mathrm{Hg}$ respectively. Blood pressure was mesured with a standard sphygmomanometer (cuff $25 \times 12 \mathrm{~cm}$ ) in the right arm with the patient seated and his/her arm resting on a desk for at least $5 \mathrm{~min}$. Diastolic blood pressure was recorded at the disappearance of the Korotkoff sounds (phase V). Diagnosis of microalbuminuria was made when the mean urinary albumin excretion in three $24 \mathrm{~h}$ urine collections performed at home during normal activity was $30-300 \mathrm{mg} /$ day [17].

\section{Protocol}

The study was carried out in a randomised two-way crossover and double-blind fashion, using a double dummy technique. Each patient received placebos on a single-blind basis for 2 weeks as a control runin phase. Patients were then randomly allocated to receive either active enalapril with nicardipine-placebo or active nicardipine with enalapril-placebo. Four patients first received enalapril as the first active drug, followed immediately by nicardipine as the second active drug. The remaining four patients were treated in the reverse order. Placebo preparations of enalapril and nicardipine were identical to the respective active tablets. The placebo wash-out period was not located between the two active-drug phases to avoid a possible withdrawal or rebound phenomenon [18]. Such a study design, without a double blind placebo period between the active treatment phases, appears to be ethically reasonably [19]. The initial dosages of enalapril and nicardipine were $5 \mathrm{mg}$ twice daily and $20 \mathrm{mg}$ trice daily, and these were increased to $10 \mathrm{mg}$ twice daily and $40 \mathrm{mg}$ trice daily, respectively during the 2 week titration period in patients whose diastolic or systolic blood pressure remained above $95 \mathrm{~mm} \mathrm{Hg}$ or $160 \mathrm{~mm} \mathrm{Hg}$, respectively. These titrating dosage schemes have been reported to be effective for lowering blood pressure in essential hypertension [20,21].

Renal function tests were examined at the end of 2 week control run-in phase and of 4 week fixed maintenance phases of enalapril and nicardipine. Blood samples for measurements of plasma renin activity (PRA), aldosterone concentration (PAC), osmotic pressure, serum total protein concentration and $\mathrm{HbA}_{1 \mathrm{c}}$ and urine samples for measurement of albumin excretion rate (AER) were collected during the 120 min renal function study. The final dose of placebo, enalapril or nicardipine was administered at 08.00 hours on the last day of each trial period. Renal function measurements were started at 12.00 hours and made in the recumbent position after $60 \mathrm{~min}$ of supine rest.

Side effects reported by the patients at each of the clinical visits were recorded by one of the investigators but were not evaluated rigorously according to special ascertainment methodology.

\section{Measurements}

Renal blood flow (RBF) and glomerular filtration rate (GFR) were measured by means of renal clearance methods using sodium paraaminohippurate and sodium thiosulfate according to the techniques as described in our previous reports $[16,22]$. Total renal vascular resistance (TRR) was calculated by the following formula [23]: (mean blood pressure - renal venous pressure) $\times 8 \times 10^{4} / \mathrm{RBF}$ (dyne $\cdot \mathrm{s}^{-1} \cdot \mathrm{cm}^{-5}$ ), where the mean blood pressure was calculated as diastolic blood pressure plus one-third pulse pressure and the renal venous pressure was substituted by $10 \mathrm{~mm} \mathrm{Hg}$. Filtration fraction (FF) was expressed as the GFR/renal plasma flow (RPF) ratio. Fractional clearance of albumin was calculated as the clearance of albumin/GFR.

Serum total protein concentration was measured in an Auto-Analyzer (SMAC I, Technicon, Tarrytown, NY, USA). PRA [24], PAC [25] and urinary albumin (normal range $0.3-13.4 \mu \mathrm{g} / \mathrm{min}$ [26] were measured by the respective radioimmunoassay. $\mathrm{Hb}_{1 \mathrm{c}}$ was measured by high-performance liquid chromatography [27] on a cation-exchange minicolumn (Auto $\mathrm{A}_{1 \mathrm{c}} \mathrm{HA}-8110$, Kyoto Daiichi Kagaku, Kyoto, Japan) (normal range $3.3-5.2 \%$ of total). Plasma osmotic pressure was determined by the freezing point method [28] in an Osmotic Pressure AUTO \& STAT OM-6010 (Kyoto Daiichi Kagaku, Kyoto, Japan).

\section{Statistical analysis}

All data are presented as means (SEM), except for AER, fractional clearance of albumin, TRR and PRA, which are shown as median and range values because of their skew distributions. Differences in measurements among the three trial phases are assessed by one-way layout analysis of variance (ANOVA), and where the overall difference between phases proved to be significant, comparison was made by the least significant difference (LSD) method. The correlation between the drug-induced change (\%) in AER and FF or TRR was analysed by Spearman's method with calculation of the rank coefficient value $\left(r_{\mathrm{s}}\right)$. All statistical analysis were performed with a PC-9801 computer (NEC, Tokyo, Japan). A $p$ value less than 5\% was considered significant. 
Table 2. Haemodynamic and renal effects of enalapril and nicardipine in 7 hypertensive Type 2 (non-insulin-dependent) diabetic patients with microalbuminuria

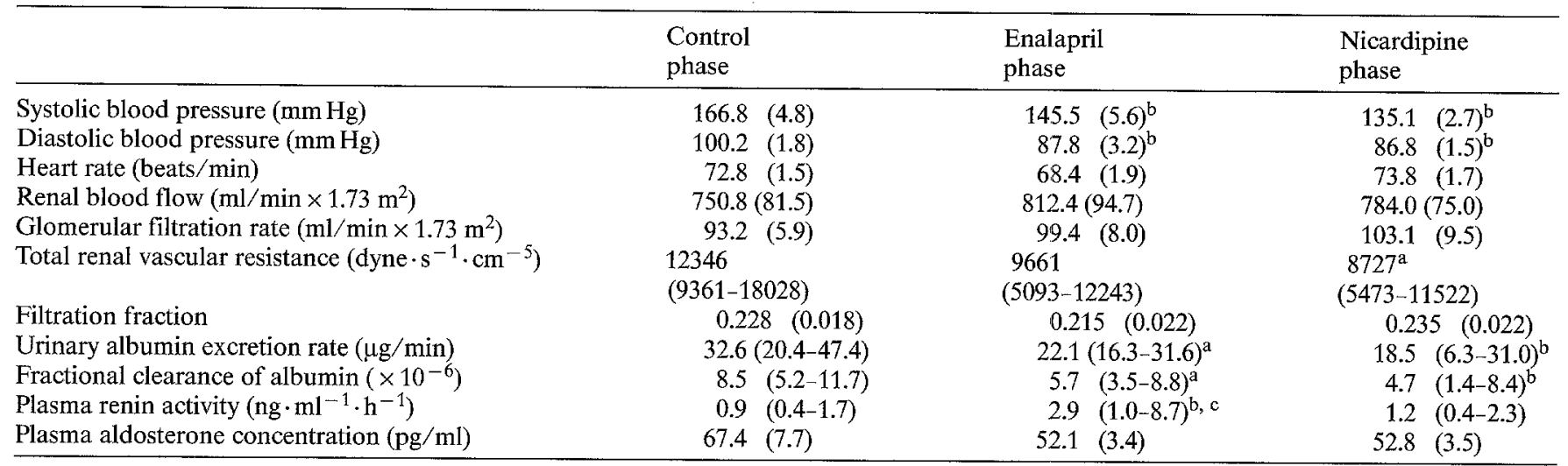

Value are given as means (SEM) or (range). ${ }^{\mathrm{a}} p<0.05$ from control phase; ${ }^{\mathrm{b}} p<0.01$ from control phase; ${ }^{\mathrm{c}}<0.05$ from nicardipine phase. Urinary albumin excretion rate and fractional clearance of albumin were assessed during the renal function tests performed in recumbent position

\section{Results}

Seven of 8 patients completed the whole course of the trials. One female patient was withdrawn from the study because she developed an intolerable cough three weeks after the initiation of enalapril. The cough diminished 2 days after the cessation of the therapy. One male patient complained of palpitation on the first day of nicardipine, in whom treatment was continued with unchanged dosage and the symptom lessened. Therefore, data reported here come from the seven patients who completed the entire trial. The clinical characteristics of the seven patients are summarised in Table 1. Data for blood pressure, body mass index, serum creatinine and AER were obtained before each patient was enrolled in the study.

Haemodynamic and renal function parameters, AER, PRA and PAC measured on the final days of the three trial phases are summarised in Table 2. The oral administrations of enalapril and nicardipine significantly reduced $(p<0.01)$ both systolic and diastolic blood pressures, respectively as compared to the control values. Systolic blood pressure in the enalapril phase was slightly, but not significantly, higher than that in the nicardipine phase. Heart rate measured at the same times was affected by neither drugs. Two patients required $10 \mathrm{mg} /$ day and five required $20 \mathrm{mg} /$ day enalapril, while four required $60 \mathrm{mg} /$ day and three did $120 \mathrm{mg} /$ day nicardipine to achieve the satisfactory blood pressure control.

Both RBF and GFR increased slightly by treatments with enalapril and nicardipine. However, the changes in RBF and GFR produced by these drugs in individual patient were inconsistent or variable and the mean RBF and GFR did not differ in the three trials. In contrast, five patients on enalapril and all patients on nicardipine showed a decrease in TRR. The mean TRR was significantly lower $(p<0.05,-25.4[7.7] \%)$ in the nicardipine phase and non-significantly lower $(-18.4[9.9] \%)$ in the enalapril phase than in the control phase. The mean value for FF remained unchanged in the three phases. Both AER and fractional clearance of albumin decreased significantly by enalapril $(p<0.05)$ and nicardipine $(p<0.01)$ respectively. The values for TRR, AER and fractional clearance of albumin did not differ in the enalapril and nicardipine phases. There was no significant correlation between the drug-induced changes in AER and FF $\left(r_{\mathrm{s}}=-0.0714\right.$ on enalapril, $r_{\mathrm{s}}=-0.3571$ on nicardipine) or TRR $\left(r_{\mathrm{s}}=0.4642\right.$ on enalapril, $r_{\mathrm{s}}=-0.4642$ on nicardipine) in this small group. PRA in the enalapril phase was significantly higher $(p<0.05)$ than those in the control and nicardipine phases respectively, while PAC remained unchanged in the three phases.

The respective values for the mean plasma osmotic pressure (control phase vs enalapril phase vs nicardipine phase: 287.3 [1.4] vs 287.3 [1.7] vs 287.1 [1.4] $\mathrm{mOsm} / \mathrm{kg}$ plasma water), total serum protein concentration (66.7 [8] vs 67.0 [8] vs 66.3 [9] g/l), serum sodium (141.7 [0.4] vs $141.5[0.6]$ vs $141.8[0.4] \mathrm{mmol} / 1)$ and potassium $(3.9[0.1]$ vs 4.0 [0.1] vs 3.9 [0.1] $\mathrm{mmol} / \mathrm{l}$ ) did not differ significantly in the three phases. $\mathrm{HbA}_{1 \mathrm{c}}$ value was slightly, but not significantly, lower on enalapril $(5.8[0.3] \%)$ as compared to those in the control $(6.1[0.2] \%)$ and nicardipine $(6.1[0.3] \%)$ phases. Body weight did not change in the three phases. No carry-over effect on haemodynamic and renal function parameters was noted.

\section{Discussion}

Oral administration of enalapril and nicardipine reduced both systolic and diastolic blood pressures in the seven hypertensive Type 2 diabetic patients with microalbuminuria. The hypotensive effect of these drugs are similar to those observed previously with enalapril in hypertensive Type 1 (insulin-dependent) diabetic patients [9] and nicardipine in patients with essential hypertension [14]. The slight difference in magnitude of blood pressure reduction might be due to differences in 
the vasodilating potency of the two agents at the doses employed. Patients' PRA profile [29], vascular distensibility [30] could also influence the hypotensive effect of these drugs.

The renal haemodynamic response to enalapril and nicardipine were similar in our patients. Such renal effects of the drugs (i.e. unchanged or slight increase in RBF and decrease in TRR) can be explained by renal vasodilatation induced by these drugs and autoregulation of renal circulation. In fact, oral administration of enalapril [31,32] and nicardipine [14] have been reported to maintain RBF and GFR with a reduction in renal vascular resistance in patients with essential hypertension. Since increased renal vascular resistance has been reported as an underlying haemodynamic abnormality in microalbuminuric diabetic patients with minimally elevated blood pressure levels [33], the finding that these drugs caused a reduction in blood pressure and TRR in hypertensive diabetic patients might be promising. Nevertheless, whether these drugs restitute GFR without inducing further glomerular damage is a remaining question. And whether the drug-induced slight increment in RBF would be harmful in terms of the current concern about glomerular hyperfiltration in diabetic patients possibly being involved with progression of diabetic nephropathy [18] remains to be determined.

The mean AER and fractional clearance of albumin decreased similarly by both enalapril and nicardipine therapies. The observation is consistent with a previous report that blood pressure control is an important factor in reducing urinary albumin excretion in hypertensive diabetic patients with microalbuminuria [33]. The present study, however, cannot totally exclude a possibility that an ACE inhibitor might cause more profound reduction in AER when $24 \mathrm{~h}$ urine samples are used, which include influence of posture, exercise and/or daily life activity. These physical activity could stimulate the production of angiotensin II, and ACE inhibitor could suppress its production. It is not known yet, however, whether such an effect on the intra- and extrarenal renin-angiotensin systems in a long-term use would cause any benefit or harm to the diabetic complications. Dietary protein is another determinant of albuminuria [34, 35]. Nevertheless, it seems unlikely that the reduction in albuminuria can be entirely explained by a change in dietary protein intake during the trials. The study was a within-subject comparison and, if the possible variability in protein intake would have existed during the control phase in each patient, the similar variability would have occurred in the same individuals during the active drug phases. The lower AER in the control phase (Table 2) as compared to the pretrial AER (Table 1) can be explained by the differences in patients' position and magnitude of physical activity during the urine collection $[36,37]$.

Hypertension is a risk factor of cardiovascular events in Type 2 diabetic patients with microalbuminuria [38]. It seems established that high blood pressure in these patients should be adequately controlled, regardless its pathophysiological mechanism(s) behind the development of hypertension. If the ultimate basis of antihypertensive therapy is not only to lower blood pressure, but also to include preservation of regional circulation, the use of the drugs, which interfere with one or more vasoconstrictor mechanisms in order to reverse the underlying renal haemodynamic abnormality, might be a logical approach. However, the present findings should be interpreted with some caution. First, patients must be followed for severel years until reliable and meaningful data may be obtained [39] to evaluate whether a treatment is truly beneficial for the patients or not. Second, Parving et al. showed that effective antihypertensive treatment with metoprolol, hydralazin and furosemide could slow the progression of nephropathy $[5,40]$. The rate of decline in GFR with those drugs $\left(0.37 \mathrm{ml} \cdot \mathrm{min}^{-1} \cdot\right.$ month $^{-1}[40], 0.22 \mathrm{ml} \cdot \mathrm{min}^{-1}$ - month ${ }^{-1}$ [5], $0.49 \mathrm{ml} \cdot \mathrm{min}^{-1} \cdot \mathrm{month}^{-1}$ [3]) appears to be comparable to the rate with enalapril $(0.40 \mathrm{ml}$. $\mathrm{min}^{-1} \cdot$ month $^{-1}$ [41], $0.20 \mathrm{ml} \cdot \mathrm{min}^{-1} \cdot$ month $^{-1}$ [7]). These observations might suggest that the beneficial effect of antihypertensive treatment on renal function is related to the good control of blood pressure rather than to the class of drug used.

In conclusion, we did not find any difference in renal effects of enalapril and nicardipine in this shortterm study with hypertensive Type 2 diabetic patients with microalbuminuria. It remains to be seen whether the initiation of antihypertensive treatment with ACE inhibitor or calcium antagonist at an early stage of nephropathy would have a more effective long-term beneficial impact over other antihypertensive agents on the progression of nephropathy and cardiovascular morbidity and mortality in diabetic patients. Until further studies ascertain the long-term renal functional effectiveness and safety of these drugs in diabetic patients over a wide range of nephropathy and hypertension, our results should be viewed as a preliminary basis for future studies.

Acknowledgments. We thank Mrs. H. Soma for her skillful nursing assistance. We would also like to thank Dr. M. Berger and Dr. I. Mühlhauser for their advice and help in preparing the manuscript and Dr. T.Tomiyama, Dr. T. Ishizaki and Mrs. Y.Baba for their. invaluable cooperation to the study. Yamanouchi Pharmaceutical Co., Tokyo, Japan, and Banyu Seiyaku Co., Tokyo, Japan, kindly donated the placebo tablets of nicardipine (Yamanouchi) and enalapril (Banyu) used in the study. This study was partly supported by the Alexander von Humboldt Foundation, Bonn, FRG.

\section{References}

1. The Working Group on Hypertension in Diabetes (1987) Statement on hypertension in diabetes. Diabetes Care 10:764-776

2. Pell S, D'Alonzo CA (1967) Some aspects of hypertension in diabets mellitus. J Am Med Assoc 202: 104-110

3. Mogensen CE (1982) Long-term antihypertensive treatment inhibiting progression of diabetic nephropathy. $\mathrm{Br}$ Med $\mathbf{J} 285$ : $685-688$ 
4. Parving H-H, Andersen AR, Smidt UM, Svendsen PAa (1983) Early and aggressive antihypertensive treatment reduces rate of decline in kidney function in diabetic nephropathy. Lancet I: $1175-1178$

5. Parving H-H, Andersen AR, Smidt UM, Hommel E, Mathiesen ER, Sevendsen PA (1987) Effect of antihypertensive treatment on kidney functionin diabetic nephropathy. $\mathrm{Br}$ Med J 294: 1143-1447

6. Hommel E, Parving H-H, Mathiesen E, Edsbert B, Nielsen MD, Giese J (1986) Effect of captopril on kidney function in insulin-dependent diabetic patients with nephropathy. Br Med J 293: $467-470$

7. Björck S, Nyberg G, Mulec H, Granerus G, Herlitz H, Aurell M (1986) Beneficial effects of angiotensin converting enzyme inhibition on renal function in patients with diabetic nephropathy. $\mathrm{Br}$ Med J 293: 471-474

8. Passa P, LeBlanc H, Marre M (1987) Effects of enalapril in insulin-dependent diabetic subjects with mild to moderate uncomplicated hypertension. Diabetes Care 10: 200-204

9. Marre M, LeBlanc H, Suarez L, Guyenne T, Ménard J, Passa P (1987) Converting enzyme inhibition and kidney function in normotensive diabetic patients with persistent microalbuminuria. $\mathrm{Br}$ Med J 294: 1448-1452

10. Jarret RJ (1984) The epidemiology of coronary heart disease and related factors in the context of diabetes mellitus and impaired glucose tolerance. In: Jarrett RJ (ed) Diabetes and heart disease. Elsevier, Amsterdam, pp 1-23

11. Khan MIG (1985) Manual of cardiac drug therapy. Bailliére Tindall, Eastbourne, pp 1-33

12. Pedrinelli R, Fouad FM, Tarazi RC, Bravo EL, Textor SC (1986) Nitrendipine, a calcium-entry blocker: renal and humoral effects in human arterial hypertension. Arch Intern Med 146: 62-65

13. Sunderrajan S, Reams G, Bauer JH (1987) Long-term renal effects of diltiazem in essential hypertension. Am Heart J 114: 383-388

14. Baba T, Ishizaki T, Murabayashi S, Aoyagi K, Tamasawa N, Takebe K (1987) Multiple oral doses of nicardipine, a calciumentry blocker: effects on renal function, plasma renin activity, and aldosterone concentration in mild-to-moderate essential hypertension. Clin Pharmacol Ther 42: 232-239

15. Reams G, Hamory A, Lau A, Bauer JH (1988) Effect of nifedipine on renal function in patients with essential hypertension. Hypertension 11: 452-456

16. Baba T, Boku A, Ishizaki T, Sone K, Takebe K (1986) Renal effects of nicardipine in patients with mild-to-moderate essential hypertension. Am Heart J 111: 552-557

17. Mogensen CE, Christensen CK (1980) Predicting diabetic nephropathy in insulin-dependent patients. N Engl $\mathrm{J}$ Med 311: $89-93$

18. Houston MC (1981) Abrupt cessation of treatment in hypertension: consideration of clinical features, mechanisms, prevention and management of the discontinuation syndrome. Am Heart $J$ 102: $415-430$

19. Jackson G, Harry JD, Robinson C, Kitson D, Jewitt E (1978) Comparison of atenolol with propranolol in the treatment of angina pectoris with special reference to once daily administration of atenolol. Br Heart J 40: 998-1004

20. van Schalk BAM, Geyskes GG, Kettner N, Boer P, Mees EJD (1986) Comparison of enalapril and propranolol in essential hypertension. Eur J Clin Pharmacol 29: 511-516

21. Taylor SH, Frais MA, Lee P, Verma SP, Jackson N, Silke B (1985) Anti-hypertensive dose-response effects of nicardipine in stable essential hypertension. Br J Clin Pharmacol 20: 135S-138S

22. Baba T, Ishizaki T, Ido Y, Aoyagi K, Murabayashi S, Takebe $K$ (1986) Renal effects of nicardipine, a calcium entry blocker, in hypertensive Type II diabetic patients with nephropathy. Diabetes 35: 1206-1214

23. Willassen Y, Ofstad J (1983) Intrarenal pressure and sodium excretion in hypertension of chronic glomerulonephritis in humans. Hypertension 5: 375-384
24. Haber E; Koerner T, Page LB, Klinman B, Purnode A (1969) Application of a radioimmunoassay for angiotensin I to the physiologic measurements of plasma renin activity in normal human subjects. J Clin Endocrinol Metab 29: 1349-1355

25. Ogihara T, Iinuma K, Nishi K, Arakawa Y, Takagi A, Kurata K, Miyai K, Kumahara Y (1977) A non-chromatographic non-extraction radioimmunoassay for serum aldosterone. J Clin Endocrinol Metab 45: 726-731

26. Miles DW, Mogensen CE, Gundersen HJG (1979) Radioimmunoassay for urinary albumin using a single antibody. Scand J Clin Lab Invest 26: 5-11

27. Davis JE, McDonald JM, Jarrett L (1978) A high-performance liquid chromatography method for hemoglobin $\mathrm{A}_{1 \mathrm{c}}$. Diabetes 27 : 102-107

28. Mercier DE, Feld RD, Witte DL (1978) Comparison of dew-point and freezing point osmometry. Am J Med Tech 44: 1066-1069

29. Resnick LM, Nicholson JP, Laragh JH (1987) Calcium, the reninaldosterone system, and the hypotensive response to nifedipine. Hypertension 10: 254-258

30. Faris I, Agerskov K, Henrikson O, Lassen NA, Parving $\mathrm{H}-\mathrm{H}$ (1982) Decreased distensibility of a passive vascular bed in diabetes mellitus: an indicator of microangiopathy? Diabetologia 23: $411-414$

31. Simon G, Morioka S, Snyder DK, Cohn JN (1983) Increased renal plasma flow in long-term enalapril treatment of hypertension. Clin Pharmacol Ther 34: 459-465

32. O'Connor DT, Mosley CA, Cervenka J, Bernstein KN (1984) Contrasting renal haemodynamic responses to the angiotensin converting enzyme inhibitor enalapril and the beta-adrenergic antagonist metoprolol in essential hypertension. J Hypertension [Suppl 2]: 89-92

33. Christensen C, Mogensen CE (1985) Effect of antihypertensive treatment on progression of incipient diabetic nephropathy. Hypertension 7 [Suppl II]: 109-113

34. Wiseman MJ, Bognetti E, Dodds R, Keen H, Viberti GC (1987) Changes in renal function in response to protein restricted diet in Type 1 (insulin-dependent) diabetic patients. Diabetologia 30: 154-159

35. Kupin WL, Cortes P, Dumler F, Feldkamp CS, Lilates MC, Levin NW (1987) Effect on renal function of changes from high to moderate protein intake in Type 1 diabetic patients. Diabetes 36: 73-79

36. Mogensen CE (1971) Urinary albumin excretion in early and long-term juvenile diabetes. Scand J Clin Lab Invest 28: 183-193

37. Viberti GC, Jarrett RJ, McCartney M, Keen H (1978) Increased glomerular permeability to albumin induced by exercise in diabetic subjects. Diabetologia 14: 293-300

38. Mattock MB, Keen H, Viberti GC, El-Gohari MR, Murrells TJ, Scott GS, Wing JR, Jackson PG (1988) Coronary heart disease and urinary albumin excretion rate in Type 2 (non-insulin-dependent) diabetic patients. Diabetologia 31:82-87

39. Mühlhauser I, Bruckner J, Howorka K (1987) Near-normoglycaemia and microvascular complications. Diabetologia 30: 47-48

40. Parving H-H, Andersen AR, Hommel E, Smidt U (1985) Effects of longterm antihypertensive treatment on kidney function in diabetic nephropathy. Hypertension 7 [SuppI II]: 114-117

41. Parving H-H, Hommel E, Smidt UM (1988) Angiotensin converting enzyme inhibitor protects kidney function and reduces albuminuria in diabetic nephropathy. Diabetologia $31: 530 \mathrm{~A}$

Received: 29 September 1988

and in revised form: 3 December 1988

Dr. Tsuneharu Baba

Medizinische Klinik der Universität Düsseldorf

Abteilung für Stoffwechsel und Ernährung

Moorenstraße 5

D-4000 Düsseldorf

FRG 